\title{
Awareness of breast cancer among females with breast diseases
}

\author{
Lakmini Mudduwa ${ }^{1}$, Champa Wijesinghe ${ }^{2}$ \\ ${ }^{1}$ Senior Lecturer in Pathology, ${ }^{2}$ Lecturer in Community Medicine, Faculty of Medicine, University of \\ Ruhuna, Karapitiya, Galle.
}

\begin{abstract}
Introduction: Breast cancer is the commonest cancer among females. Women need to be aware about the clinical symptoms and course of the disease to increase the chances of early detection of breast cancer and thereby to reduce mortality due to it.
\end{abstract}

Objective: To assess the knowledge of breast cancer among females with breast diseases.

Method: All patients seeking treatment for a breast disease during a period of two years from two surgical units were included in the study. A pre-tested, structured, interviewer administered questionnaire was used to collect data on the knowledge of breast cancer. The participants were inquired about the awareness, symptoms, risk factors, early detection, modes of spread and treatment of breast cancer.

Results: Out of 126 patients included in the study $111(88 \%)$ had heard or read about breast cancer. The print and electronic media were the leading sources of information. Breast lump was the best known symptom. The most known risk factor was the positive family history. The majority (77.7\%) knew that the early detection of breast cancer could increase the chances of cure. Although $69.8 \%$ of the participants knew that breast cancer can spread, the exact modes of spread of breast cancer were not well known. Only $8.7 \%$ did not know about the kind of therapy available for breast cancer. The knowledge of breast cancer declined with the decrease in the educational level $(\mathrm{p}<0.05)$.

Conclusions: A satisfactory knowledge was present among the females participated. The future breast cancer awareness programmes need to emphasize on addressing the women with lower educational standards.

\section{Introduction}

Breast cancer is the commonest cancer among Sri Lankan women and women world over ${ }^{1,2}$. According to the most recent statistics for Sri Lanka, the incidence of breast cancer in the female population was 9.82 per 100,000 population in the year 1995 . The estimated lifetime risk was $1.35 \%$. The commonest age group affected was 40-49 years. Almost half (49.7\%) of the affected were less than 50 years of age ${ }^{2}$.

In Sri Lanka, a higher proportion of younger females are affected compared to the rest of the world ${ }^{3}$. Most of the patients are detected at an advanced stage of the cancer ${ }^{4}$. This lowers the 5 years survival and limits the opportunity for modern therapeutic modalities which are designed to retain the cosmetic outlook.

There is no national breast cancer screening programme in Sri Lanka. However, information on breast cancer is available to the public on print and electronic media. Well Women Clinics are another source of information on breast cancer as the healthcare workers are expected to give information on such health issues in addition to screening women for diabetes mellitus, hypertension, cervical carcinoma and breast carcinoma.

The aim of this study was to assess the knowledge of breast cancer among females with breast disease in a sample of females in Sri Lanka. This study may provide useful information in designing future breast cancer awareness programmes.

\section{Method}

The present study was carried out at the Teaching Hospital Karapitiya, Galle. All patients seeking treatment for a breast disease from 
August 2005 to March 2007 at the Professorial Surgical Unit and one other surgical unit were included in the study. The instrument used for data collection was an interviewer administered structured questionnaire developed by the authors. The questionnaire was translated into Sinhala and pre-tested. The questionnaire consisted of questions designed to assess the awareness and knowledge about symptoms, common risk factors (positive family history, exposure to radiation and nulliparity), early detection, modes of spread and treatment of breast cancer. The association between the knowledge and the educational level of the participants was analysed using Chi square test.

Pre-intern doctors interviewed the patients during their stay in the ward. Informed written consent was obtained from each patient prior to the interview. Ethical approval for the study was granted by the Ethical Review Committee of the Faculty of Medicine, Galle.

\section{Results}

Hundred and twenty six patients (126) with an age range of 13 to 75 years were included in the study. There were $52(41.3 \%)$ married women. Only $3(2.4 \%)$ patients stated having no formal education while the majority $(73.8 \%)$ had either General Certificate of Education Ordinary Level (G.C.E. O/L) or a higher standard of education.

This study sample included 63 patients with a histopathological diagnosis of a benign breast lesion and 30 patients with breast carcinoma. The histopathological diagnosis was not available for the other patients. Most of the patients included in the study $(51.5 \%)$ were self referrals. There were $111(88.1 \%)$ patients who had recognized symptoms of breast disease incidentally while five patients have found lumps in the breast following self breast examination. Three patients had their breast lumps detected at medical examinations.

\section{Awareness of breast cancer}

There were 111 patients (88\%) who had heard or read something about breast cancer. Out of the total number of patients $78(61.9 \%)$ and 75 $(59.5 \%)$ had stated print media and electronic media respectively as sources of information on breast cancer. A friend or a relative had been the source of information in $38(30.1 \%)$ patients. Forty two patients (33.3\%) had received information from healthcare personnel.

\section{Symptoms}

Breast lump was the best known symptom and it was admitted by 94 (74.6\%) patients. Fifty two patients $(41.2 \%)$ knew that nipple discharge is a symptom of breast cancer. The least known symptom was ulceration of the skin over the breast, which was known to $12.6 \%$ of the participants.

\section{Risk factors}

Of the subjects, $42.8 \%$ knew that a positive family history is a risk factor and it is the most known among the risk factors. Thirty (23.8\%) patients believed that the use of oral contraceptive pills is associated with breast cancer. Nulliparity and exposure to radiation were stated as risk factors by $27(21.4 \%)$ and 17 (13.49\%) patients, respectively. The least known risk factor was early menarche which was known only to two patients $(1.5 \%)$.

\section{Early detection of breast cancer}

Out of the total number of participants, 98 (77.7\%) knew that the early detection of breast cancer could increase the chances of cure. Only 45 patients $(35.7 \%)$ had heard about self breast examination. However, only 5 (3.9\%) patients declared that they practiced it regularly. There were $15(11.9 \%)$ patients who practiced self breast examination, but not regularly.

\section{Spread of cancer}

There were $88(69.8 \%)$ patients who knew that breast cancer can spread to the other sites of the body. Most of them did not know how it occurs (46.8\%). Twenty two patients (17.4\%) knew that breast cancer spreads via blood and 6 (4.7\%) knew that lymphatics were a mode of spread. 


\section{Treatment of breast cancer}

Surgery as a treatment for breast cancer was known to 97 (76.9\%). Radiotherapy as a mode of therapy was known to 60 patients $(47.6 \%)$. Only $32.5 \%$ knew about chemotherapy. Eleven patients $(8.7 \%)$ did not have any idea about what kind of therapy was available for breast cancer.
All aspects of knowledge assessed in this study except nulliparity as a risk factor had a significant association with the educational standards $(\mathrm{p}<0.05)$. The knowledge declined with the decrease in the educational standards (Table 1).

Table 1 - The distribution of knowledge about the factors assessed according to the level of education.

\begin{tabular}{|c|c|c|c|c|c|c|}
\hline Factors assessed & $\begin{array}{c}\text { Higher } \\
\text { educatio } \\
n(n=8)\end{array}$ & $\begin{array}{c}\text { GCE } \\
\text { Advance } \\
\text { d Level } \\
(n=49) \\
\end{array}$ & $\begin{array}{c}\text { GCE } \\
\text { Ordinary } \\
\text { Level } \\
(\mathbf{n}=\mathbf{3 6}) \\
\end{array}$ & $\begin{array}{c}\text { Grade } \\
5-10 \\
(\mathbf{n}=21) \\
\end{array}$ & $\begin{array}{c}\text { Grade 1- } \\
4(n=9)\end{array}$ & $\begin{array}{c}\text { No } \\
\text { educatio } \\
\mathbf{n}(\mathbf{n}=\mathbf{3})\end{array}$ \\
\hline & $\mathbf{n}(\%)$ & $\mathbf{n}(\%)$ & $\mathrm{n}(\%)$ & $\mathbf{n}(\%)$ & $\mathrm{n}(\%)$ & $\mathrm{n}(\%)$ \\
\hline $\begin{array}{l}\text { Awareness about breast } \\
\text { cancer* }\end{array}$ & $8(100)$ & $41(83.6)$ & $22(61.1)$ & $11(52.3)$ & $4(44.4)$ & $2(66.6)$ \\
\hline \multicolumn{7}{|l|}{ Knowledge on symptoms } \\
\hline Breast lump* & $8(100.0)$ & $38(77.6)$ & $32(88.9)$ & $11(52.4)$ & $3(33.3)$ & $2(66.7)$ \\
\hline Ulceration* & $3(37.5)$ & $5(10.2)$ & $3(8.3)$ & $2(9.5)$ & $1(11.1)$ & $2(66.7)$ \\
\hline Nipple discharge* & $5(62.5)$ & $23(46.9)$ & $17(47.2)$ & $6(28.6)$ & $0(0.0)$ & $1(33.3)$ \\
\hline Change in shape* & $4(50.0)$ & $9(18.4)$ & $8(22.2)$ & $1(4.8)$ & $0(0.0)$ & $0(0.0)$ \\
\hline Pain* & $5(62.5)$ & $8(16.3)$ & $7(19.4)$ & $2(9.5)$ & $0(0.0)$ & $0(0.0)$ \\
\hline \multicolumn{7}{|l|}{ Knowledge on risk factors } \\
\hline $\begin{array}{l}\text { Positive family } \\
\text { history* }\end{array}$ & $5(62.5)$ & $23(46.9)$ & $19(52.7)$ & $5(23.8)$ & $1(11.1)$ & $0(0.0)$ \\
\hline $\begin{array}{l}\text { Exposure to } \\
\text { radiation* }\end{array}$ & $5(62.5)$ & $10(20.4)$ & $4(11.1)$ & $0(0.0)$ & $0(0.0)$ & $0(0.0)$ \\
\hline Nulliparity & $3(37.5)$ & $15(30.6)$ & $7(19.4)$ & $2(9.5)$ & $0(0.0)$ & $0(0.0)$ \\
\hline \multicolumn{7}{|l|}{ Knowledge on treatment } \\
\hline Drugs* & $5(62.5)$ & $19(38.7)$ & $9(25.0)$ & $5(23.8)$ & $2(22.0)$ & $1(33.3)$ \\
\hline Surgery* & $7(87.5)$ & $43(87.0)$ & $31(86.1)$ & $11(52.3)$ & $3(33.3)$ & $3(100)$ \\
\hline Radiotherapy* & $7(87.5)$ & $26(53.0)$ & $16(44.4)$ & $8(38.0)$ & $3(33.3)$ & $0(0.0)$ \\
\hline \multicolumn{7}{|l|}{ Knowledge on } \\
\hline Spread of cancer* & $8(100)$ & $41(83.6)$ & $22(61.1)$ & $11(52.3)$ & $4(44.4)$ & $2(66.6)$ \\
\hline Early detection* & $7(87.5)$ & $44(89.7)$ & $29(80.5)$ & $13(61.9)$ & $4(44.4)$ & $1(33.3)$ \\
\hline $\begin{array}{l}\text { Self breast } \\
\text { examination* }\end{array}$ & $7(87.5)$ & $14(28.50$ & $13(36.1)$ & $7(33.3)$ & $3(33.3)$ & $1(33.3)$ \\
\hline
\end{tabular}

*Association was significant at $p<0.05$ 


\section{Discussion}

Formal education provides an advantage in the understanding of various health issues ${ }^{1}$. This study reveals that the majority seeking treatment for breast cancer in the study sample had a minimum of G.C.E. O/L as an educational qualification. There were only three patients who had no formal education. This is a reflection of the high literacy rate in Sri Lanka. It was $89.7 \%$ for females in the Year $2001{ }^{5}$. Galle district which is served by the Teaching Hospital, where the study was conducted had a literacy rate of $91.5 \%$ for females in the same year which was higher compared to the rate for the whole country ${ }^{5}$.

This study reveals that the print and electronic media were the leading source of information on breast cancer for the patents included in our study. The print media which was one of the sources of information for most of the patients $(61.9 \%)$ in the sample can be explained by the high literacy rate. A health personnel as a source of information was admitted by only $33.3 \%$ of patients. Friends and relations has been the source for $30.1 \%$ of patients. The role played by healthcare personnel in educating women about breast cancer cannot be claimed unsatisfactory but can be improved.

A high proportion of patients (88\%) were aware of breast cancer and a $77.7 \%$ were aware that early detection of cancer increases the chances of cure. The possibility of breast cancer spreading to other sites of the body was known to $69.8 \%$. Therefore, a high proportion of patients in the study had a fair knowledge about breast cancer.

Self referral being the commonest among the referral methods, it is consistent with the satisfactory knowledge of the population studied. However, other than a positive family history, the risk factors of breast cancer were not very well known. A study done in Ireland had shown very much similar results with regard to the awareness of breast cancer, leading sources of information and risk factors ${ }^{6}$.

The knowledge about self breast examination among the study population was poor compared to the others factors assessed. Most women in the study population had referred themselves to the hospital following to accidental finding of a breast lump.
Although breast self-examination is often advocated as a non-invasive screening test, most women do not regularly perform it. A large study conducted over 10 years showed that a formal programme of teaching breast selfexamination has no effect on breast cancer mortality but may produce a small reduction in overall mortality ${ }^{7}$. A Cochrane review concluded that breast self-examination has no beneficial effect and actually increase the number of biopsies performed ${ }^{8}$. Therefore, some authors do not recommend regular self breast examination.

The National Health Service (NHS), United Kingdom emphasises the importance of "Breast Awareness" which is about encouraging women to become more aware of their bodies generally and to get to know their own breasts. They emphasize that there is no scientific evidence to show that a formally taught, ritual selfexamination performed at the same time each month, reduces the death rate from breast cancer or is more effective than breast awareness ${ }^{9}$.

NHS Breast Screening Programme and Cancer Research UK, sets out a five- point plan for women ${ }^{10}$.

1. Know what is normal for you.

2. Look and feel.

3. Know what changes to look for.

4. Report any changes without delay.

5. Attend for breast screening if aged 50 or over.

The last step is not applicable in Sri Lanka at the moment as we are yet to set up a National Breast Cancer Screening Programme. However, to be "breast aware" women need to know the importance of it. Therefore, it is essential to have a satisfactory knowledge of breast cancer.

\section{Conclusions}

A satisfactory knowledge was present among the females participated. The decrease in the knowledge of breast cancer with the decrease in the educational level emphasizes the need to strengthen the public awareness programmes concentrating more on the women with a lower educational background. 


\section{Acknowledgement}

Consultant surgeons of the Teaching Hospital Karapitiya who gave access to interview their patients, Demonstrators of the Department of Pathology who collected the data and Mrs. I. Lokuge for the support given in typing the manuscript and the questionnaire, are acknowledged.

\section{References}

1. Oluwatosin OA, Oladepo O. Knowledge of breast cancer and its early detection measures among rural women in Akinyele Local Government Area, Ibadan, Nigeria. BMC Cancer 2006; 6: 271-7.

2. National Cancer Control Programme. Cancer Registry 1995, Cancer incidence 1995; Colombo Sri Lanka.

3. Mudduwa LKB, Mangalika SAM, Kohomban CJ, et al. Breast cancer screening; what age group should be targeted? Galle Medical Journal 2000; 2(1): 60-2.
4. Ratnayake P, Mudduwa LKB. Clinicopathological features of breast carcinoma; an analysis of 96 patients. Proceedings of the Annual Academic Sessions of the College of Pathologists of Sri Lanka 2003: p15.

5. Department of Census and Statistics. Statistical Abstract 2007, Ministry of Finances and Planning, Colombo. Sri Lanka.

6. McMenamin M, Barry H, Lennon A, et al. A survey of breast cancer awareness and knowledge in a western population: lots of light but little illumination. European Journal of Cancer 2005; 41: 393-7.

7. Barry H. Breast self-examination does not reduce mortality. American Family Physician 2003; 67(8): 1784.

8. Kosters JP, Gotzsche PC. Regular self-examination or clinical examination for early detection of breast cancer. Cochrane Database System Review 2003; 2: CD003373.

9. National Health Service Breast Screening Programme. Breast Screening: a pocket guide. 2008 Department of Health. Sheffield, United Kingdom. 